\title{
Os corpos de Ulisses geografia e história da subjetividade moderna
}

\author{
PAULO GHIRALDELLIJR.
}

RESUMO: O artigo trata da formação da subjetividade moderna e seus desdobramentos no mundo contemporâneo. O tema é abordado a partir da "questão do corpo", segundo o que se pode inferir da leitura da Odisséia feita por Horkheimer e Adorno.

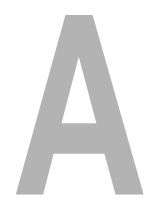

"É o baixo ventre que impede o homem de considerar-se um deus" - escreve Nietzsche em Para além do bem e do mal. De um certo modo, a filosofia de Adorno e de Horkheimeré, toda ela, um grande comentário desta frase de Nietzsche. Segundo esta frase, a presença do corpo lembraria ao homem sua condição terrena. Ora, Adorno e Horkheimer acreditam que, ao contrário, a presença do baixo ventre foi o que sempre impulsionou o homem ao céu, o que sempre fez dele um ser desejoso de ser deus, de livrar-se tanto das dores quanto dos prazeres que ameaçam sua unidade subjetiva, conquistada a duras penas na transição do mundo da natureza para o mundo da cultura. Durante um bom tempo, o homem tentou ser deus através da filosofia. Todavia, em um determinado dia, ele acordou na condição divina, e quando passeou pela cidade que habitava percebeu que ela garantia esta sua condição, e com uma vantagem, não precisava mais gastar tempo com a filosofia, com o pensamento. Para Adorno e Horkheimer o que houve foi a dessomatização da alma e a desespiritualização do corpo. Com isto, o homem, agora tornado só corpo - o corpo desencantado -, acredita poder ser feliz, viver num mundo mais leve, mais suave, no qual ele pode dispor de si mesmo e dos outros como coisas - que todos somos, mesmo. E, ao mesmo tempo, ser mais decidido - no limite, cruel.
UNITERIMOS: subjetividade moderna, corpo, modernidade.

Professor da Faculdade de Filosofia e Ciências da UNESP/Marília 
Adorno e Horkheimer escolhem o canto de Homero para descreverem tudo isto, que eles consideram o advento dos tempos modernos e a configuração do nosso tempo.

Quando Ulisses aporta em Ítaca, é reconhecido apenas pelo seu cão Argos, que identifica seu cheiro, e pela sua velha serva, devido a uma cicatriz de infância. No término da viagem, ao herói não é concedida uma identidade senão por indicações corporais. Assim, se Horkheimer e Adorno vêem em Ulisses o protótipo do homem moderno - enquanto burguês e Aufklärer-, é possível acrescentar que, nos momentos finais da Odisséia, Ulisses se torna de fato plenamente moderno, contemporâneo mesmo, na medida em que, como o homem do século XX, vê sua subjetividade-identidade deslocada para o corpo. Se nos nossos tempos modernos cada um é o que é o seu corpo, o que ocorre com Ulisses confirma, um pouco para além do que escrevem os dois frankfurtianos, a idéia que eles tiveram ao verem na viagem do herói a protohistória da formação da subjetividade moderna bem como seu destino (cf. Horkheimer \& Adorno, 1986).

No entanto, se a viagem de Ulisses é a proto-história do sujeito moderno, ao fim e ao cabo, estando a subjetividade assentada no corpo, há de se desconfiar de que alguma coisa não saiu como o esperado - pelo menos não saiu segundo as promessas oficiais do Iluminismo e de alguns de seus arautos e defensores, que disseram aos quatro cantos que nos livraríamos da menoridade e nos tomaríamos indivíduos autênticos se tivéssemos a coragem de nos guiarmos pelo nosso próprio entendimento. Ora, para onde vão o entendimento, o intelecto, a razão, se a subjetividade é calcada no corpo?

Horkheimer duvida da possibilidade de uma identidade subjetiva dada pelo corpo. Há, diz ele, uma debilidade nessa via que vê no corpo a possibilidade de um novo substrato da identidade: "o corpo possui, nas diversas etapas da vida, uma unidade de todo modo duvidosa", pois, a "unidade da vida individual não é natural, mas conceitual, quer dizer, socialmente mediatizada" (Horkheimer, 1973, p. 158). Em que medida haveria lugar para o sapere aude! kantiano se não podemos contar com uma unidade subjetiva à base do intelecto, da razão? Como crer que Ulisses seja moderno e Aufklärer exatamente quando ele parece portar características contrárias às prometidas - pelo menos as oficialmente prometidas - pelo Humanismo e pela Modernidade? Ou, em outras palavras: como Ulisses saiu da menoridade se o preço para tal foi o de tornar-se só corpo e, portanto, deixar de lado o entendimento, justamente a faculdade que, no seu uso corajoso pelo homem, teria sido a garantia para que ele, Ulisses, e nós, atravessássemos o portal dos tempos modernos enquanto sujeitos?

Ulisses em Ítaca não é o fim verdadeiro da Odisséia, mas seu início: é agora que o Humanismo tem de se explicar. Afinal, Ulisses, tendo aportado 
na sua terra natal, é ou não é moderno? A pergunta nos encaminha para este único elemento que restou sob a vista: o corpo de Ulisses, que passa a ser a geografia e a história da subjetividade moderna.

\section{II}

Quando Ulisses deixa Tróia em direção à Ítaca, não faz idéia do que terá, ainda, de enfrentar. O Destino lhe reserva um percurso de aventuras e escolhe Homero menos para cantá-las do que para nos fornecer um tratado de psicofisiologia. Como aquele soldado que volta carente de vivências ricas da Primeira Guerra Mundial, do qual fala Walter Benjamin, Ulisses, que deveria, ao fim da viagem, estar nutrido das mais ricas experiências - pois, afinal, ninguém viveu mais aventuras que ele -, na verdade está tão pobre delas quanto seus remadores que, com os ouvidos tapados com cera, puderam conduzir o navio para longe do Mar das Sereias. Se a experiência com o pedaço de cera pôde mostrar a Descartes que é mais fácil conhecer a alma que o corpo, a cera imposta aos ouvidos dos trabalhadores de Ulisses nos mostra que a eles não será dada a oportunidade de qualquer conhecimento, nem o da alma nem o do corpo - a experiência com o pedaço de cera é em Descartes e Ulisses, por motivos ainda que diferentes, o fim de toda e qualquer experiência. Ulisses, por sua vez, não se utiliza, obviamente, da cera, mas de cordas para se prender ao mastro. Mas seu estratagema é de tal ordem, isto é, é da ordem do desencantamento do mundo, que houve quem desconfiasse - Kafka, por sinal - que ele jamais ouviu o canto das Sereias (cf. Matos, 1993, p. 169-170). Seu corpo - o objeto do tratado de psicofisiologia de Homero - nos revela, então, a geografia e a história da dor inerente à experiência. Ou melhor: a geografia e a história do escamoteamento da dor e de sua exclusão na produção do homem emancipado, do Aufklärer - o que tem corpo e alma desencantados.

Escamoteamento - eis então uma palavra que tem tudo a ver com Ulisses. A matreira raposa, desde o início, estava destinada a restringir a razão em favor de sua forma: a instrumentalidade. Mesmo Homero, e também nós, seus ouvintes, sempre estivemos como candidatos a vítimas de alguma empulhação. Nunca soubemos, de fato, quem era Ulisses, pois seu corpo, o que, afinal, como no nosso próprio caso, é o que o identifica, jamais se apresentou sem ambigüidades. Não só as potências míticas, mas também a esposa do herói, Homero e nós - inclusive Kafka - nunca pudemos optar por uma via de leitura segura do grande tratado de psicofisiologia cantado nas terras gregas. $\mathrm{O}$ "tratado das paixões da alma", de Ulisses, é, antes de tudo, a imposição da indecidibilidade sobre três questões: o corpo de Ulisses é forte ou fraco? Morto ou vivo? Natural ou cultural? Horkheimer e Adorno percorrem cada uma delas.

\section{III}

Ulisses é forte ou fraco? É o herói forte quando vence o mendigo, mas, como sabemos, fisicamente fraco diante das potências míticas. Como 
autoconservação e força física se separam - tanto na viagem de Ulisses quanto no desdobramento da civilização -, as habilidades atléticas de Ulisses são as do gentleman, que livre do trabalho pôde se adestrar e, assim, provar sua nobreza aos atrasados e indisciplinados. Contra as potências míticas, no entanto, essas habilidades físicas devem ser postas de lado, pois nenhuma simbologia civilizada sensibiliza tais potências, de modo que as novas habilidades apresentadas são as que caracterizam o fraco, isto é, a participação fraudulenta no ritual sacrificial sem qualquer pudor, dado que o próprio ritual, para os olhos que vêem o mundo desencantado, como os de Ulisses, é já, em si, uma fraude (cf. Horkheimer \& Adorno, 1986, p. 61-62).

Ulisses é vivo ou morto? Se os remadores do navio aparecem como máquinas, se não podem se falar porque estão atrelados a um compasso, assim como os operários na fábrica moderna, no cinema e no coletivo, também Ulisses vê seu pensamento limitado na medida em que se restringe à administração e à organização. Todos têm sua experiência reduzida. "Quanto mais complicada e mais refinada a aparelhagem social, econômica e científica, para cujo manejo o corpo já há muito foi ajustado pelo sistema de produção, tanto mais empobrecidas as vivências de que ele é capaz" (Horkheimer \& Adorno, 1986, p. 47). Remadores e proprietário do navio, apesar de aos primeiros estarem destinadas as tarefas mais próximas do sensível e ao segundo as tarefas mais espirituais, têm seus corpos — sem os quais, obviamente, as vivências não ocorrem - incapazes de vivências. No entanto, se apresentam em estado de contínuo exercício; afinal, "quanto mais os organismos estão próximos da morte, tanto mais regridem ao estado de convulsões" (Adorno, 1992, p. 202).

Por fim, Ulisses é um ser da natureza ou da cultura? Ulisses vence a natureza e sucumbe a ela: vence, pois torna-se um eu, distinguindo-se dela, no entanto, quando retoma à Ítaca, não deixa de ser duro, tão duro quanto, outrora, fôra para consigo próprio e para com os companheiros, aliás, espelhando o comportamento da natureza e dos mitos para com ele e seus companheiros. Se, como diz Horkheimer, o corpo é um grande "órgão de expressão mimética" (Horkheimer, 1976, p. 125), então é ele que copia a natureza no que ela possui de destrutiva, contra os homens. Assim, o herói se utiliza das convenções e invoca tradições estabelecidas - o âmbito da cultura - para legitimar o sangue que irá arrancar de outros, e o faz, então, como no registro do Castelo Libertino, que ao buscar transcender a condição humana toma os artifícios no sentido de imitar a natureza no seu ritmo de destruição, promovendo a destruição para se adiantar a ela (cf. Moraes, 1994, p. 105-7). No limite, Ulisses adota na prática o que Sade tinha também em teoria: a idéia da natureza enquanto instância da crueldade. Se Ulisses foi considerado por alguns um deus, talvez isso tenha ocorrido pelo fato de que ele pôde, vivendo na cultura, perceber que é só ela que "conhece o corpo como algo que se pode possuir" (Horkheimer \& Adorno, 1986, p. 217), de modo que não hesitou em tomar o corpo, seu de outrem, como objeto, como artifício que imita a natureza para realizá-la enquanto instância da crueldade e, assim, vencê-la. Ulisses se põe divino - "Divino Marquês". 
Essas três questões são, na verdade, desdobramentos de uma única: afinal, o corpo de Ulisses é encantado ou desencantado? A ambigüidade permanece: Ulisses aparece como religioso e Aufklärer.

$\mathrm{O}$ homem religioso vive aberto ao Cosmos. Experiencia-o como uma situação que lhe possibilita comunicação com os deuses e participação na santidade do mundo. Assim, faz o mesmo com sua habitação e com seu corpo; toma-os como microcosmos. "Como o Cosmo, o corpo é, em última instância, uma 'situação', um sistema de condicionamentos que se assume”. O homem religioso se 'cosmiza', "reproduz, em escala humana, o sistema dos condicionamentos recíprocos e dos ritmos que caracteriza e constitui um 'mundo', que define, em suma, o universo" (Eliade, 1992, p. 139-140). Ora, o corpo de Ulisses está em abertura para o Cosmos - natureza e sociedade-, o que é possível de notar na medida em que o vemos lutando contra todas manifestações do seu corpo, que parecem forças dispostas a reintegrá-lo completamente nos ritmos do mundo encantado. Concomitantemente, o corpo de Ulisses não raro se apresenta funcional - ele é um atleta, como os libertinos e também como "homem forte" segundo Descartes -, digno daquele que deseja ser chamado de indivíduo. Mas é claro que, nesse caso, não se põe como indivíduo sem o pagamento de quantia significativa, que é a própria perda da individualidade e a composição de uma subjetividade psicológica que Homero só pôde descrever admitindo poucas camadas sobrepostas (Auerbach, 1987, p. 10). Nos termos de Horkheimer e Adorno, o resultado da reificação de corpo e alma.

\section{IV}

Mil e um corpos possui, então, Ulisses. Mil e um Ulisses, como é próprio de uma matreira raposa, de um deus e de um... sujeito. Cai por terra a noção moderna de sujeito - o homem como autor de suas idéias e de seus atos - na medida mesmo em que ela se realiza, ou parece se realizar. Ulisses, enquanto sujeito, não é, para Horkheimer e Adorno, como talvez fosse para Foucault, uma mera ficção (cf. Honneth, 1983). Mais se aproxima de uma ideologia: uma meia verdade do Iluminismo. Mas, por vários ângulos, poderíamos, foucaultianamente, dizer: o corpo de Ulisses, tão substancial durante toda a Odisséia, é inapreensível enquanto substância, porque, na verdade, pertence a uma teia de relações. Como num jogo de palitos, ao fime ao cabo, quando tiramos todos eles, o que resta é o vazio. Sua última relação, com o olfato do cão e com a percepção da cicatriz pela velha serva, mais uma vez nada mostra de seguro, pois se nesta relação Ulisses é avaliado como um ser da natureza, a avaliação é, então, pouco confiável, pelo menos para nós, que vimos quanto ele só pode ser reduzido ao corpo na medida em que adentrou o mundo da cultura.

No entanto, seria um erro tomar os mil e um corpos de Ulisses como disfarces que, no limite, nada são. Ao longo e ao fim da viagem, algo se mantém, se localizando crescentemente, nas entranhas de sua subjetividade, istoé, de seu 
Recebido para publicação em novembro/1995

UNITERIVS:

modern subjectivity,

body,

modernity.

corpo: a "frieza burguesa"- que Adorno teme como ninguém mais - e a "feliz apatia" - o destino que os personagens de Sade queriam dar aos sentimentos (cf. Ghiraldelli, 1995). Ulisses é plenamente moderno? Se sim, então a Modernidade é uma época de movimento e agitação, de festa, mas com espírito plúmbeo: a "sociedade administrada", de Adorno. Ora, e não era assim que Ulisses enxergou Ítaca, totalmente envolta por uma nuvem da deusa Atena?

GHIRALDELLI JR., Paulo. The bodies of Ulisses: geography and history of modern subjectivity. Tempo Social; Rev. Sociol. USP, S. Paulo, 8(1): 195-200, May 1996.

\section{BIBLIOGRAFIA}

AdORno, Theodor W. (1992) Minima moralia. São Paulo, Ática.

Auerbach, Erich. (1987) Mimesis. São Paulo,/Perspectiva.

Eliade, Mircea. (1992) O sagrado e o profano. São Paulo, Martins Fontes.

Ghiraldelli JR., Paulo. (1995) A modernidade e o 'interesse pelo corpo' em Horkheimer e Adorno. São Paulo. Dissertação (Mestrado). Departamento de Filosofia, FFLCH-USP.

Honneth, Axel. (1983) Foucault e Adorno: duas formas de crítica da modernidade. Revista de Comunicação e linguagem, Lisboa, $\mathrm{n}^{\circ}$ 19, p. 171-181. Dezembro

HorkHeImer, Max. (1973) Teoria crítica. Barcelona, Barral.

. (1978) Eclipse da razão. Rio de Janeiro, Editorial Labor do Brasil.

Horkheimer, Max \& Adorno, Theodor W. (1986) Dialética do esclarecimento. Rio de Janeiro, Jorge Zahar Editores.

Matos, Olgária C. Féres. (1993) O iluminismo visionário: Benjamin, leitor de Descartes e Kant. São Paulo, Brasiliense.

MoraEs, Eliane Robert de. (1994) Sade: a felicidade libertina. Rio de Janeiro, Imago. 